\title{
Mobile English Teaching System Based on Adaptive Algorithm
}

https://doi.org/10.3991/ijet.v13i08.9057

\author{
Xing Zhao \\ Baoji University of Arts and Sciences, Baoji, China \\ zhaoxing209@sina.com
}

\begin{abstract}
To improve the students' individualized and autonomous learning ability in English teaching, a mobile English learning system is designed on the basis of adaptive algorithm. The students' need for the adaptive mobile English teaching system is analyzed through researches on students and questionnaires. According to the needs analysis, the main functional modules of the adaptive mobile English learning system are designed, including the creation module, personalized learning module, evaluation and feedback module, and management module. Then, the improved XAHM (XML adaptive hypermedia model) is applied to the mobile English learning system. The three-layer architecture of the English mobile learning system is revised into four layers of composition layer, data layer, business logic layer and presentation layer. At the same time, more attention is diverted to the terminal and the situation. Finally, the system is tested. The test results showed that the mobile English learning system realized the self-adaptive and intelligent navigation of learning space in the course of teaching. It is concluded that the new adaptive algorithm had a good performance for college English learning.
\end{abstract}

Keywords-Self-adaptive, English learning, mobile English teaching, XAHM

\section{Introduction}

Nowadays, mobile computing devices and mobile learning applications are becoming more and more popular, and mobile communication tariff is reduced. At the same time, people have gained more lifelong learning awareness, so mobile learning has embedded in people's work, study and life in formal or informal ways. In addition, mobile learning related researches have also attracted attention from experts and scholars. College students were one of active powers in mobile learning, and in turn, mobile learning also provides new means and ways for their English learning. This advances the implementation of the college English curriculum advocated by the ministry of education. Based on the computer and classroom teaching model, they guide students to carry out individualized teaching and self-study to broaden their horizons.

In order to ensure the mobile English learning system is teaching students in accordance with their aptitude, adaptive learning has become one of the most important foci. Adaptive learning means that under the guidance and help of teachers, students 
acquire and analyze feedback information by interacting with subsystems such as adaptive tests, teaching strategies, teaching methods, and learning evaluation systems in an adaptive learning system. They can choose the most suitable learning content and method, control and adjust the learning process in time so as to meet the optimal learning goals for themselves. In essence, it breaks through the connotation of traditional learning, and it is a new learning concept and learning mode. It will be the main trend of mobile English teaching mode in the future. Based on the adaptive algorithm, this paper analyzes and designs the mobile English learning system.

\section{State of the art}

Foreign countries are in the upsurge of research in the study of adaptive learning and system development. Yousefi, R. et al. [1] proposed a novel real-time adaptive algorithm. The theme of the research project funded by National Institute Standards and Technology Advanced Technology Program in 1998 was the adaptive learning system. A total of more than a dozen related studies have been funded, and tens of millions of dollars have been invested in research. The main goal of the project is to accelerate the deployment of a learning system based on the network, WEB and other mobile terminals. Therefore, we should speed up the construction of national learning infrastructure. Xing M et al. [2] pointed out that video streaming was gaining popularity among mobile users. The latest mobile devices, such as smart phones and tablets, were equipped with multiple wireless network interfaces. To solve the MDP in real time, we proposed an adaptive, best-action search algorithm to obtain a sub-optimal solution. Experiment results demonstrated the feasibility and effectiveness of the proposed adaptation algorithm for mobile video streaming applications, which outperforms the existing state-of-art adaptation algorithms.

Hsu, L. [3] explained that while mobile devices were gradually starting to play an important role in students' everyday lives, learning English on mobile phones was no longer a novelty for English as a foreign language (EFL) learners. While there were many papers that discussed the application of information and communication technologies (ICTs) in EFL education, studies on mobile assisted language learning (MALL) were still in want. As a result, education and training can be widely popularized and meet individual learners' needs. At present, in China, the research on the mobile teaching system based on WEB is rising. However, the research on adaptive teaching system adapted to the needs of individual learners still lags behind. Troussas, C. et al. [4] proposed a student-oriented approach tailored to effective collaboration between students using mobile phones for language learning within the life cycle of an intelligent tutoring system.

At present, there is a large proportion of theoretical research in mobile learning research in China, but there is few in-depth and innovative research on localization. In the field of technology research, scholars have tried to introduce all kinds of high and new technology. However, the breakthroughs of the key problems in the application of this technology in mobile learning are still scarce. In the field of application and practice, some valuable cases have been formed. However, it has not yet fully 
summed up the law and enriched the experience. With the increasing attention and input of experts and scholars on mobile learning, the scope of mobile learning is expanding. However, behind the expansion, there has been a study of the essence behind mobile learning. Yarandi, M. [5] said that adaptive learning was an important research topic in the field of web-based systems as there were no fixed learning paths which were appropriate for all learners. However, most studies in this field had only focused on learning styles and habits of learners. Far too little attention had been paid on understanding their abilities. Therefore, it is becoming increasingly difficult to ignore adaptation in the field of e-learning systems.

Yang, J. [6] explained that as mobile computing technologies had been more powerful and inclusive in people's daily life, the issue of mobile assisted language learning (MALL) had also been widely explored in CALL research. Many researches on MALL considered the emerging mobile technologies had considerable potentials for effective language learning. Recent research or review on mobile assisted lan-guage learning tended to focus on more detailed applications of newly emerging mo-bile technology, rather than give a broader point focusing on types of mobile device itself.

Huang, R. T. et al. [7] pointed out that although there was a growing interest in mobile learning, there were limited studies that focused on student knowledge acquisition. As applications and usages of mobile technology had become more and more accepted, it was important and meaningful that researchers and practitioners of mobile learning underattended the potential factors that could influence learning outcomes.

Hsu, C. C. et al [8] thought that mobile learning provided a ubiquitous learning context for the learners to select appropriate learning paths and learning objects. Adaptive learning methods and correct learning path planning can help to achieve the goal of learning in anytime and anywhere. Moreover, the display ability of mobile learning devices had become a key factor affecting learners' interest and acquisition time. Achieving the desired functionality is currently an important topic in the field of mobile learning. Joseph, S. R. et al [9] explained the use of mobile devices for language learning. In particular we consider how different multimedia and interface modalities can be used to facilitate mobile language learning.

Canales, A.et al [10] pointed out our contribution to carry out adaptive and intelligent Web-based Education Systems that takes into account the individual student's learning requirements. An effective adaptive mobile learning system must be built on the basis of fully understanding subjects' requirements. It is necessary to explore specific system functions, media types, learning and practice methods for specific demand groups. Therefore, systematic research can only be carried out through combining theoretical and empirical methods. Aiming at the lack of practical research on adaptive learning and mobile learning in China, we combine self-adaptive learning with mobile learning to understand the functional needs of respondents in college English mobile learning system. The design of a mobile English learning system based on adaptive algorithm has an important practical significance for English teaching.

In view of the inadequacy of the research on adaptive mobile learning in the introduction part, based on the research experience of the above literature, this paper mainly proposes to study mobile English teaching with adaptive algorithm. On the 
one hand, research is conducted on specific groups to meet the needs of individual learners. On the other hand, the mobile English learning system has achieved selfadaptiveness in the teaching process and has great significance for English teaching. The details are described below.

\section{$3 \quad$ Method}

\subsection{Demand analysis of adaptive English mobile learning system}

This research adopts "College English Intensive Reading Palm Treasure" soft-ware in the mobile learning system. The interviewees can experience the mobile learning, fill in the questionnaire and accept depth interview. Thus, they will under-stand the needs of mobile learning and acceptance degree, expectations of mobile learning implementation methods, main situation of mobile learning, curriculum requirements of mobile learning, content and function of College English learning.

This study is carried out in the software college of a normal university. The interviewees are freshmen and sophomore students in software engineering. The English teaching material they have studied is the "Intensive Reading of College English" published by the Shanghai Foreign Language Teaching Press (Third Edition). Software majors are taken as subjects, because they can act as college student representatives who experience English mobile learning, and objectively and rationally feedback and evaluate their English learning by mobile learning. In addition, they have a certain degree of software design and development ideas and foundations. They have more acute and thorough observation and experience on system design, software function, interactive level and so on. At the same time, they are more sensitive to the new information technology, and the feedback information is more rational, scientific and effective. A stratified sampling method is used in the study. There are 21 in the first grade and 22 in the sophomore year. The effective questionnaires and interviews are 40 , and the effective rate is $93.2 \%$. The effective samples for each grade are 20 . In the effective samples, the proportion of male and female students in all grades is 1:1.

This study uses experience research and the questionnaire survey. The mobile learning system software is the "College English Intensive Reading Palm Treasure". Its content is synchronized with the course of "College English Intensive Reading" published by the Shanghai Foreign Language Teaching Press (Third Edition). Some of the second and fourth copies of the text are selected as the curriculum resources used for the experience study. The content of software learning includes words, texts, exercises and so on.

The interviewees can use the palm treasure to experience mobile learning after a brief introduction to the purpose of the study, the basic information of mobile learning, and the main purpose of this software. Through spontaneous attempts, the puzzles and problems encountered in the use process are recorded. The experience time varies from person to person, and the average time is 30 to 40 minutes. Then, the respondents will receive a questionnaire. The content involves the attitude and cognition of respondents to mobile learning, the evaluation and demand of learning content, sys- 
tem function, learning way, implementation mode, application context and functional preference of mobile learning. The understanding and attitude to mobile learning are shown in figure 1 and figure 2.

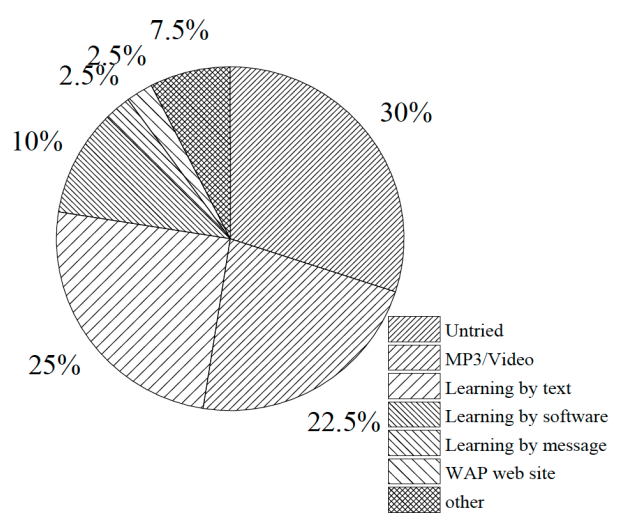

Fig. 1. Interviewees using mobile phones for learning

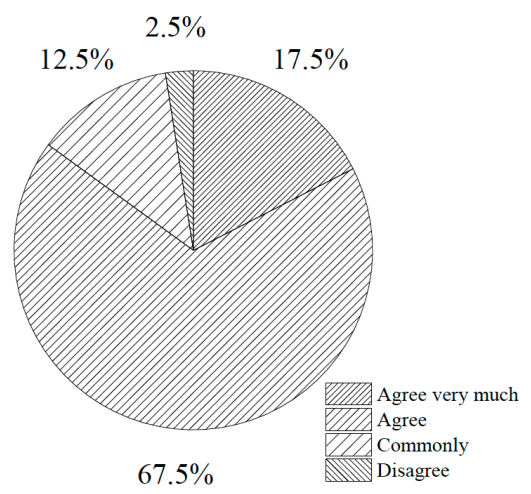

Fig. 2. Beginning to like mobile learning after use

According to figure 1 and figure 2, we can see that college students are very familiar with mobile learning and have a strong demand for mobile learning. Moreover, mobile learning can be achieved anytime and anywhere. According to the function choice of interviewees, the query function is at the top of the list, which is $77.5 \%$. The curriculum learning occupies $67.5 \%$. All kinds of exercises occupy the third, accounting for $62.5 \%$. In addition, the degree of approval of learning reminding occupies $20 \%$, while the record of achievement accounts for only $5 \%$. Combining the characteristics of the mobile learning platform, this shows that the core functions of the English mobile learning platform are query, learning and practice modules. Among them, vocabulary and listening are the core content of the development of English mobile learning course for college students. Also, mobile learning courses should be short, rich and colorful. These findings can be used as important basis for developing English mobile learning platform. 


\subsection{Functional design of adaptive English mobile learning system}

It is assumed that there are three kinds of users, students, teachers and administrators, and the relationship and interaction of the three is shown in figure 3. Students are the center of the system. They take initiatives to acquire knowledge and self-test, and can also carry out collaborative learning. Teachers guide and assist students to study and supervise students, and they also carry out teaching design and educational administration. Administrators are responsible for the maintenance of the system and the management of the information of students and teachers. The administrator can be a part of the teacher.

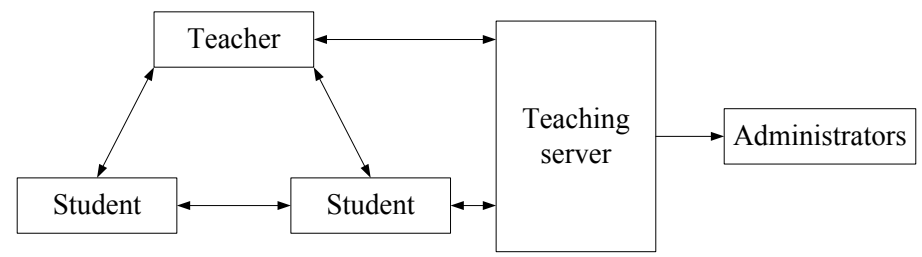

Fig. 3. Role analysis diagram in the model

The function diagram of the model is shown in figure 4 , including the creation module, the personalized learning module, the evaluation and feedback module, and the management module. Aiming at the learning terminal, each module has the limitations of small screen size, small memory capacity and low learning resources. At the same time, the module considers the respect for education and the intelligence of the system. Users can log on to the front desk to receive service and land in the background for management.

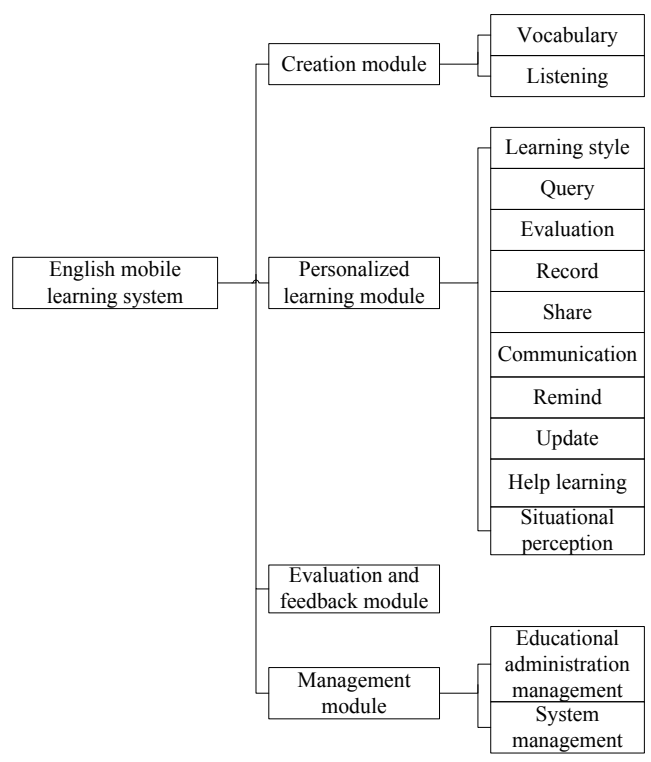

Fig. 4. System function diagram 


\subsection{XАHM adaptive reference model}

Di $\mathrm{S}$ et al [11] showed that XAHM was a more common adaptive reference model. The three most important modules are the domain model, the learner model and the adaptive learning model.

According to the different types of learners, the domain model presupposes a lot of topics corresponding to the "preset" path of EAC and PD. Maguya AS et al [12] thought that these extracted "preset" path would constitute a logical navigation graph corresponding to different types of lead users. The coupling degree $s(k)$ with each profile is judged according to the mean of the shortest path probabilities of the logical navigation map, the average length of the shortest path and the number of nodes.

$$
s(k)=\frac{\beta_{0} \mu(k)+\beta_{1} n(k)+\beta_{2} p(k)}{\beta_{0}+\beta_{1}+\beta_{2}}
$$

Ahmad MS et al [13] pointed out that the learner model can be updated when the learner requested a link each time. Of course, the update frequency or time interval can also be customized. When a learner passes through a specific path $\mathrm{Rr}-1$ and requests the next node $\mathrm{Rr}$, the probability of next node $\mathrm{Rr}$ is selected via this path according to the probability that $\mathrm{Rr}-1$ belongs to a domain path corresponding to the probability of a certain lead plate category $\mathrm{k}$. In addition, the time spent in the domain path corresponding to each lead category $\mathrm{k}$ can be used to determine the coupling degree $\mathrm{d}(\mathrm{k})$ between the learner and each lead category.

$$
d(k)=\frac{\alpha_{0} c(k)+\alpha_{1} r(k)+\alpha_{2} t(k)}{\alpha_{0}+\alpha_{1}+\alpha_{2}}
$$

Duran J et al [14] explained that in the general model, according to the initial user lead type, user's current lead membership model $\mathrm{A}(\mathrm{K})$, the $\mathrm{s}(\mathrm{k})$ and $\mathrm{d}(\mathrm{k})$, the user lead type is ultimately determined. In addition, the field learning path corresponding to the lead type is recommended to the user.

$$
A^{\prime}(k)=\frac{\gamma_{0} A_{0}(k)+\gamma_{1} A(k)+\gamma_{2} d(k)+\Delta \gamma_{3} s(k)}{\gamma_{1}+\gamma_{2}+\Delta \gamma_{3}}
$$

Zayyani $\mathrm{H}$ [15] pointed out that analysis showed that current XAHM model had the following 3 problems. Firstly, in terms of domain models, the concept layer of XAHM includes global presentation, basic abstraction, page description, content, link and layout information in pages, but, it cannot adapt to the mobile terminal which presents a small page and a large amount of mobile communication data. Secondly, in the learner, XAHM mainly from the learner's behavior to match learners under the lead type. The learner model records the lead category, the matching degree between learners and lead each category, learning path and link, stop time. It doesn't pay attention to other factors, such as learning style, and it is unable to build an effective personal mobile learning environment. Finally, in the adaptive learning path, XAHM limits the granularity to the learning path corresponding to the grid model. However, it does not take individual differences into account. Therefore, the preamble 
knowledge will be different. At the same time, it does not consider self-adaptive presentation of resources from the perspectives of learning style and learner's preference.

\subsection{Improvement of XAHM adaptive reference model}

Bapat MS et al [16] pointed out that in mobile learning environment, there are still many shortcomings in presentation and processing speed of mobile learning devices compared with traditional digital learning, especially in the process of wireless communication and multitasking. As a result, a large amount of data will be downloaded when it comes to the network communication or when the large amount of data is interacted. This will lead to a time delay, but the following data reading will be very quick. It can be transmitted in batches, so the initial content is faster, but each time will take a lot of time. Referring to a lot of mobile learning terminals, researchers find that "card" concept is used to deal with this problem in the development process. As shown in table 1, a domain model of five levels is formed.

Table 1. Analysis of five levels domain model

\begin{tabular}{|c|c|c|c|c|c|c|c|}
\hline $\begin{array}{c}\text { Num } \\
\text { ber }\end{array}$ & Name & Introduction & $\begin{array}{c}\text { Descrip- } \\
\text { tion } \\
\text { method }\end{array}$ & $\begin{array}{l}\text { Superior } \\
\text { relation- } \\
\text { ship }\end{array}$ & $\begin{array}{c}\text { Upper } \\
\text { description } \\
\text { method }\end{array}$ & $\begin{array}{l}\text { Subordi- } \\
\text { nate } \\
\text { relation- } \\
\text { ship }\end{array}$ & $\begin{array}{l}\text { Lower layer } \\
\text { description }\end{array}$ \\
\hline 0 & $\begin{array}{l}\text { Fragment } \\
\text { infor- } \\
\text { mation (IF) }\end{array}$ & $\begin{array}{l}\text { It is often the non-separable, no - } \\
\text { formattable and no-stored, such as } \\
\text { text, audio and video, pictures and } \\
\text { other related information. }\end{array}$ & XML & IC or IP & $\begin{array}{l}\text { Weighted } \\
\text { directed } \\
\text { multiplex } \\
\text { graphs with } \\
\text { signs }\end{array}$ & No & No \\
\hline 1.1 & $\begin{array}{l}\text { Card } \\
\text { infor- } \\
\text { mation } \\
\text { (IC) }\end{array}$ & $\begin{array}{l}\text { It is composed of content, layout, } \\
\text { format, access authority and so on. } \\
\text { Also, the attributes are consistent } \\
\text { with the adaptive space. It is often } \\
\text { the split of page information, and } \\
\text { the amount of information is small. }\end{array}$ & XML & IP & Linked list & IF & $\begin{array}{l}\text { Weighted } \\
\text { directed } \\
\text { multiplex } \\
\text { graphs with } \\
\text { signs }\end{array}$ \\
\hline 1.2 & $\begin{array}{c}\text { Page } \\
\text { infor- } \\
\text { mation (IP) }\end{array}$ & $\begin{array}{l}\text { It is composed of content, layout, } \\
\text { format, access authority and so on. } \\
\text { Also, the attributes are consistent } \\
\text { with the adaptive space. It is often a } \\
\text { combination of card information, } \\
\text { and the amount of information is } \\
\text { relatively large. }\end{array}$ & XML & EAC & $\begin{array}{l}\text { Weighted } \\
\text { directed } \\
\text { multiplex } \\
\text { graphs with } \\
\text { signs }\end{array}$ & IF & $\begin{array}{l}\text { Weighted } \\
\text { directed } \\
\text { multiplex } \\
\text { graphs with } \\
\text { signs }\end{array}$ \\
\hline 2 & $\begin{array}{l}\text { Basic } \\
\text { abstract } \\
\text { concepts } \\
\text { (EAC) }\end{array}$ & Made up of EAC or IP & XML & IP & $\begin{array}{l}\text { Weighted } \\
\text { directed } \\
\text { multiplex } \\
\text { graphs with } \\
\text { signs }\end{array}$ & $\mathrm{AD}$ & $\begin{array}{l}\text { Weighted } \\
\text { directed } \\
\text { multiplex } \\
\text { graphs with } \\
\text { signs }\end{array}$ \\
\hline 3 & $\begin{array}{l}\text { Applica- } \\
\text { tion area } \\
\text { (AD) }\end{array}$ & EAC structure & XML & EAC & $\begin{array}{l}\text { Weighted } \\
\text { directed } \\
\text { multiplex } \\
\text { graphs with } \\
\text { signs }\end{array}$ & - & $\begin{array}{l}\text { Weighted } \\
\text { directed } \\
\text { multiplex } \\
\text { graphs with } \\
\text { signs }\end{array}$ \\
\hline
\end{tabular}


The learner model proposed by XAHM is mainly considered from the perspec-tive of knowledge level. At the same time, the learning path and time of the learners are preserved and analyzed. Based on the learner model, the cognitive ability, lead model, environmental conditions, technical conditions and learning processes are increased, which is conducive to building a personal mobile learning environment effectively.

Zhang S et al [17] thought that in order to solve the problem that the XAHM will adapt to the granularity of the learning path corresponding to the slab model, there is no generation of personalized preamble knowledge content. At the same time, the problem of adaptive resource also is not considered. Therefore, the two-level adaptive mechanism is introduced. The first layer refers to determine the adaptive learning path level according to the degree of coupling model, domain model and user model of each type of predefined lead. The adaptation of the first level continues to continue the original foundation of XAHM. With regard to the second levels of self-adaptive, these two problems are solved.

It is assumed that the type of lead model is StereTypec. The corresponding StereType path is $(\mathrm{Rc}, 1, \ldots, \mathrm{Rc}, \mathrm{r}-1, \mathrm{Rc}, \mathrm{r})$. The problem now is to determine the specific preamble knowledge content, the links and the adaptive presentation of resources for Rc,r. Therefore, two processes are proposed to solve the problem.

Process one is that making all the required learning knowledge correspond to the calculation of Rc,r. The set of learners target knowledge points get_knowledge = $\{\mathrm{t} 1, \mathrm{t} 2, \ldots, \mathrm{tm}\}$ is determined. According to the domain model, the preamble knowledge set Pre_knowledge $=\{\mathrm{p} 1, \mathrm{p} 2, \ldots, \mathrm{pn}\}$ corresponding to the m knowledge points in the target_knowledge set is found, and pi is EAC. Finally, the learners' mastery degree of Pre_knowledge is judged one by one.

$$
\text { Pr } e_{-} \text {Know edge _Level }=\left\{\left(p_{i}, h_{i}\right) \mid p_{i} \in A D, h_{i} \in H\right\}
$$

According to the specific situation, the Pre_knowledge in a certain range is set as the target. According to the existing target, the search for Pre_knowledge is continued until there is no new knowledge points added.

Process two is the adaptive presentation of Rc,r. This involves the learners' learning styles, functions, conversational forms, and media type preferences. Here is an example of learning style, and other types of processes are no longer described. The subjection of the learners' learning style is calculated in the path that they trav-eled.

$$
s_{i}: v_{i}=\frac{\lambda * \sum_{1}^{v_{j}} t(k)+\eta * \sum_{1}^{r-1} v_{i}}{\alpha * \sum_{1}^{r-1} t(k)+\beta * \sum_{1}^{r-1} v}
$$

EAC corresponds to a number of IP. vi is matched with IP marked with learning style. This matching process may be multilevel based on EAC composition, and IP is recommended with minimum semantic distance.

$$
I P_{\mathrm{min} n_{-} \text {style }}=\dot{\mathrm{m} n}{\sqrt{\sum_{j}^{E A V}\left(v_{i}-P_{j}\right)}}^{2}
$$


A series of IP are obtained from the learners' learning style, learning back-ground, media orientation and interest and other information. In addition, the selected IP is also required to be screened in a comprehensive way. Finally, the appropriate IP is identified and presented to the learners.

$$
I P=\min \frac{\alpha * I P i_{\mathrm{min}_{-} s t y l e}+\beta * I P i_{\mathrm{min}_{-} \mathrm{fun}}+\chi * I P i_{\mathrm{min}_{-} \text {corrv }}+\delta * I P i_{\mathrm{min}_{-} \text {midum }}}{\alpha+\beta+\chi+\delta}
$$

\subsection{Structure of English mobile learning system in an adaptive perspective}

As shown in figure 5, the XAHM architecture is divided into three layers: the creation layer, the data layer and the application layer. The three-layer architecture of the English mobile learning system is revised into four layers: composition layer, data layer, business logic layer and presentation layer. Moreover, it also intuitively gives more attention to the terminal and the situation.

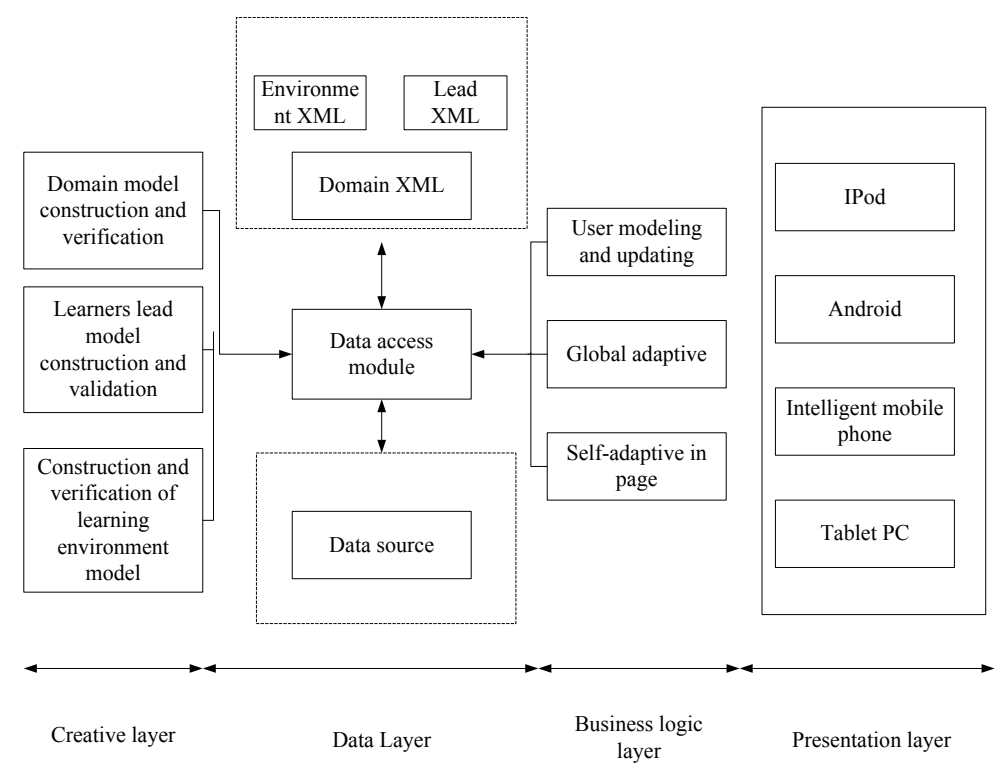

Fig. 5. Structure of English mobile learning system in an adaptive perspective

The creation layer mainly uses graphical interfaces and drag and drop operations to initialize or modify data in databases and data warehouses. The creation layer includes the construction and validation of the domain model, establishment of learner lead model, construction and validation of learning environment. The domain model will include five aspects: debris information, card information, page information, basic abstract concept information and application field. According to the learning style, learning background, media tendency and interest, and Gardiner's multiple intelligence theory, the learner lead model can specify the model and the probability 
value. According to students' choice of autonomous learning, cooperative learning, inquiry learning and other learning methods, the related learning environment is established. The roles in the model includes students, teachers and administrators. However, to a large extent, teachers and managers exist as creators and do not directly interfere with the students' learning process.

The data layer is divided into two layers: data source and data (warehouse) li-brary. Its role is not only to undertake all kinds of information that is constructed and modified by the creation layer, but also to accommodate learners' static information and dynamic learning behavior. Meanwhile, it can store system rules and labor divi-sion information in learning activities. In addition, the data layer also has an irre-placeable role in providing access to persistent data.

The business logic layer corresponds to the application layer in the XAHM, maintaining the modeling and updating of the user. The adaptation is divided into two levels. One is domain level adaptation, which is consistent with the adaptive mechanism in the XAHM. In addition, it is the adaptation of content and navigation. The other is the self-adaptive in the page, which involves the consideration of factors such as learning style and so on. In addition, the division and self-adaptive of "card" should also be included.

The presentation layer is also called the display layer, presenting the specific page / card information produced by the two-level adaption to the learner. Moreover, the presentation layer can also obtain situational information (time, location, band-width, page stop time, noisy environment) and mobile learning terminal information (operation system, screen size, processing speed, browser situation). Moreover, it uses the information to identify learners and match related models in the system to produce better adaptive effects.

\section{$4 \quad$ Result}

The system test in this paper is carried out in the software college of a normal university. The interviewees are freshmen and sophomore students in software engineering. Taking the College English Intensive Reading (Edition No.3) of Shanghai Foreign Language Teaching Press as an example, the adaptive learning process of an adaptive mobile English learning system for a knowledge point is described.

It is assumed that a student lands on an adaptive mobile English teaching system for learning. First, the system looks at the records in the learning information table. The system finds the learning breakpoint from the student's learning information table and sets the point as current learning point. Then, it will check the students' learning information table to get their teaching methods. According to teaching methods, corresponding resources are taken out from the teaching resource base to form the teaching content for students to learn. In the learning process, students can retrieve information related to the knowledge point, and enter the answering room, discussion area, and forum. They also can communicate with tutors and classmates. When the knowledge point is finished, the learning test is entered. The test questions corresponding to the knowledge point are extracted from the question bank, and the test is 
carried out. The test results are evaluated according to the evaluation algorithm, and then the students' cognitive ability is deduced according to the evaluation rules.

Table 2. Evaluation results of cognitive ability

\begin{tabular}{|l|c|c|c|c|}
\hline \multicolumn{1}{|c|}{ Type } & Actual score & Relative score & Weighted score & Evaluation result \\
\hline Memorizing questions & 6 & 40 & 16 & Middle \\
\hline Understanding questions & 15 & 75 & 15 & High \\
\hline Application question & 15 & 50 & 10 & Middle \\
\hline Analysis question & 20 & 80 & 8 & High \\
\hline Comprehensive question & 7 & 70 & 7 & High \\
\hline Total score & 63 & & 57 & \\
\hline
\end{tabular}

After the end of the evaluation, the learning path is determined according to the results of the evaluation information. For this study, if the student's academic performance is 63 , student can enter the next knowledge point of study according to the teaching strategy rules. The knowledge branch cutting method is used to redefine the reachable knowledge point set CLOSED. Then, it also needs to search the knowledge tree to find the next suitable knowledge point according to the depth first search strategy. At the same time, the node is recorded in the learning history item of the student's learning table.

After the readjustment of the learning path, the teaching method should be adjusted again. According to the evaluation results of cognitive ability, the students choose a kind of teaching method suitable for the individual according to the rules of teaching methods. In this case, student's learning ability is reduced. Therefore, his or her next teaching method is to choose the learning emphasis with deep level. Then, students can continue to carry on the adaptive learning of the next knowledge point. At the same time, students learn the teaching methods of the knowledge point and the evaluation of learning cognitive ability to update the relevant data items in their learning table.

The above is an adaptive learning process that takes the "single branch" as an example. The test shows that the system has two main functions, namely, the adaptive presentation of the learning content and the intelligent navigation of the learning space in the teaching process of mobile English.

According to different students' cognitive abilities, knowledge mastery and learning progress, the system can dynamically present the most appropriate teaching content to the current learning ability of learners. At the same time, hypermedia is used to provide students with illustrated explanations of images and texts in order to stimulate students' interest in learning and motivation.

\section{Conclusion}

In this paper, a mobile English learning system is designed based on adaptive algorithm. Through the study of students' experience and questionnaire, we conclude the following findings. 
Firstly, the core functions of the English mobile learning platform are the mod-ules of inquiry, learning and practice. Among them, vocabulary and listening are the core content of the development of English mobile learning course for college stu-dents.

Secondly, according to the results of needs analysis, the main functional modules of the adaptive mobile English learning system are designed, including the creation module, the personalized learning module, the evaluation and feedback module, and the management module.

Thirdly, the improved XAHM adaptive model is applied to the mobile English learning system. At the same time, the three-layer architecture of English mobile learning system is revised to the four-layer structure, including creation layer, data layer, business logic layer and presentation layer, which gives more attention to terminal and context.

Finally, the system is tested. The test results show that the mobile English learn-ing system designed in this paper has realized the self-adaptive and intelligent naviga-tion of learning space in the course of teaching.

\section{References}

[1] Yousefi R, Nourani M, Ostadabbas S, et al. A motion-tolerant adaptive algorithm for wearable photoplethysmographic biosensors. IEEE Journal of Biomedical \& Health Informatics. 2014, vol. 18(2), pp. 670. https://doi.org/10.1109/JBHI.2013.2264358

[2] Xing M, Xiang S, Cai L. A Real-Time Adaptive Algorithm for Video Streaming over Multiple Wireless Access Networks. IEEE Journal on Selected Areas in Communications. 2014, vol. 32(4), pp. 795-805. https://doi.org/10.1109/JSAC.2014.140411

[3] Hsu, L. English as a foreign language learners' perception of mobile assisted language learning: a cross-national study. Computer assisted language learning. 2013, vol. 26(3), pp. 197-213. https://doi.org/10.1080/09588221.2011.649485

[4] Troussas, C., Virvou, M., \& Alepis, E. Collaborative learning: Group interaction in an intelligent mobile-assisted multiple language learning system. Informatics in Education. 2014, vol. 13(2), pp. 279. https://doi.org/10.15388/infedu.2014.08

[5] Yarandi, M., Jahankhani, H., \& Tawil, A. R. H. A personalized adaptive e-learning approach based on semantic web technology. webology. 2013, vol. 10(2), pp. 1.

[6] Yang, J. Mobile assisted language learning: review of the recent applications of emerging mobile technologies.English Language Teaching. 2013, vol. 6(7), pp. 19. https://doi.org/10.5539/elt.v6n7p19

[7] Huang, R. T., Jang, S. J., Machtmes, K., \& Deggs, D. Investigating the roles of perceived playfulness, resistance to change and self - management of learning in mobile English learning outcome. British Journal of Educational Technology. 2012, vol. 43(6), pp. 10041015. https://doi.org/10.1111/j.1467-8535.2011.01239.x

[8] Hsu, C. C., \& Ho, C. C. The design and implementation of a competency-based intelligent mobile learning system.Expert Systems with Applications. 2012, vol. 39(9), pp. 80308043. https://doi.org/10.1016/j.eswa.2012.01.130

[9] Joseph, S. R., \& Uther, M. Mobile devices for language learning: Multimedia approaches. Research and Practice in Technology Enhanced Learning. 2009, vol. 4(01), pp. 7-32. https://doi.org/10.1142/S179320680900060X

[10] Canales, A., Peña, A., Peredo, R., Sossa, H., \& Gutiérrez, A. Adaptive and intelligent web based education system: Towards an integral architecture and framework. Expert Systems 
Paper-Mobile English Teaching System Based on Adaptive Algorithm

with Applications. 2007, vol. 33(4), pp. 1076-1089. https://doi.org/10.1016/j.eswa.2006.08.034

[11] Di S, Wang CL, Cappello F. Adaptive Algorithm for Minimizing Cloud Task Length with Prediction Errors. IEEE Transactions on Cloud Computing. 2014, vol. 2(2), pp. 194-207. https://doi.org/10.1109/TCC.2013.16

[12] Maguya AS, Junttila V, Kauranne T. Adaptive algorithm for large scale dtm interpolation from lidar data for forestry applications in steep forested terrain. Isprs Journal of Photogrammetry \& Remote Sensing. 2013, vol. 85(85), pp. 74-83. https://doi.org/10.1016/j.isp rsjprs.2013.08.005

[13] Ahmad MS, Kukrer O, Hocanin A. A 2-D recursive inverse adaptive algorithm. Signal Image \& Video Processing. 2013, vol. 7(2), pp. 221-226. https://doi.org/10.1007/s11760-0110218-8

[14] Duran J, Buades A. Self-similarity and Spectral Correlation Adaptive Algorithm for Color Demosaicking. IEEE Transactions on Image Processing a Publication of the IEEE Signal Processing Society. 2014, vol. 23(9), pp. 4031-4040. https://doi.org/10.1109/TIP.2014 .2341928

[15] Zayyani H. Continuous Mixed \$p\$-Norm Adaptive Algorithm for System Identification. IEEE Signal Processing Letters. 2014, vol. 21(9), pp. 1108-1110. https://doi.org/10.1109/ LSP.2014.2325495

\section{$7 \quad$ Authors}

Xing Zhao, College of foreign languages, Baoji University of arts and sciences, Baoji, China. Research direction is the study of Chinese and Western Literature

Article submitted 23 April 2018. Resubmitted 15 May 2018. Final acceptance 28 June 2018. Final version published as resubmitted by the author. 